\title{
Correspondence
}

\section{In vitro fertilisation conference}

SIR

Thank you for publishing Mr Justice

Kirby's report of the Conference on Bioethics and Law of Human Conception in Vitro sponsored by Mogul International in 1983. There are some points which I think need comment.

Referring to Dr Whitehead's contribution Judge Kirby states 'there are however some who hold the view that infertility is often a punishment for promiscuity. Upon this view, infertility should not be relieved lest promiscuity, forbidden by scripture, be unpunished where nature has rendered its verdict'. Although I understand from Judge Kirby that this view has been expressed in Australia, I think it only right to point out that I have never heard it expressed in all the discussions concering IVF in which I have participated in recent years, nor was it stated by any participant at the conference, except by Judge Kirby himself.

Further on, in referring to my own contribution, the Judge reports that I 'urged attention to the causes of infertility, particularly venereal disease, abortion and IUDs'. My argument was that a responsible health education approach to these areas could prevent many of these cases of infertility and, also, that there should be a positive approach to infertility counselling. Further in the same paragraph he suggests that I wished to return to the days prior to the sexual revolution. Being a Christian I have to be an eternal optimist and hope and trust that there is a real possibility of society looking for what is right and not continually yielding to current pressures and phases. Judge Kirby also states that I would find 'morally acceptable the simple family-saving case of IVF that is implantation of all embryos created by husband and wife bound together by marriage'. By this statement I did not mean that I would find acceptable the use of super-ovulatory drugs to enable the procurement and fertilisation of several ova.

I thought I should write at length to explain this to set the record straight. I feel at the same time I should comment that Judge Kirby's condensation of a very packed two-day conference was a remarkable achievement.

MONSIGNOR M F CONNELLY Secretary, Catholic Bishops' Joint Committee on Bio-Ethical Issues 